\title{
A prática de individualização de crânios e de decapitação na região de Lagoa Santa durante o Holoceno Inicial (Brasil)
}

\author{
André Strauss * \\ Rodrigo Elias Oliveira* *
}

STRAUSS, A.; OLIVEIRA, R.E. A prática de individualização e de decapitação na região de Lagoa Santa durante o Holoceno Inicial (Brasil). R. Museu Arq. Etn., 28: 86-108, 2017.

Resumo: Por mais envoltos que estivessem em práticas cruéis de flagelação humana, os europeus ficaram fascinados com os costumes ameríndios que envolviam a remoção e a exibição de partes do corpo humano, especialmente quando a prática da decapitação ou individualização de crânios estava presente. Na América do Sul, o caso mais antigo de decapitação é relatado na região andina com ca. 3000 AP no sítio Ásia 1 (Peru). Uma vez que quase todos os outros casos arqueológicos da América do Sul também ocorreram nos Andes (por exemplo, Nazca, Moche, Huari e Tiahuanaco), assumiu-se que a decapitação foi um fenômeno andino, tanto em suas origens como em sua expressão mais inequívoca. Esta contribuição tem como objetivo avaliar as evidências disponíveis sobre a decapitação na América do Sul e relatar a descoberta no Brasil de diversos casos de crânios individualizados, que estão datados em torno de 9000-9500 cal BP (intervalo de 95,4\%). Escavados no abrigo da Lapa do Santo, em Lagoa Santa (MG), esses casos de crânios individualizados incluem a decapitação mais antiga do Novo Mundo, implicando uma reavaliação da origem e da dispersão geográfica desse fenômeno no continente.

Palavras-chave: Arqueologia; Antropologia; História; Ritual; Lapa do Santo.

Dor mais envoltos que estivessem em práticas cruéis de flagelação do corpo humano, os europeus ficaram fascinados com os costumes ameríndios envolvendo a remoção e a exibição de partes do corpo humano,

\footnotetext{
* Paleoanthropology, Senckenberg Center for Human Evolution and Paleoenvironment, Eberhard Karls University of Tübingen; Centro de Arqueologia Annette Laming-Emperaire; Max Planck Institute for Evolutionary Anthropology, Department of Human Evolution; Universidade de São Paulo, Departamento de Genética e Biologia Evolutiva.<strauss@usp.br>

** Universidade de São Paulo, Faculdade de Odontologia, Periodontia; Centro de Arqueologia Annette LamingEmperaire.<eliaso@usp.br>
}

especialmente quando a prática da decapitação ou individualização de crânios estava presente (Chacon \& Dye 2007). Embora contestado por alguns autores (e.g. Ferguson 1990), tornouse amplamente aceito que tais práticas eram comuns entre os nativos americanos em todo o continente e as evidências arqueológicas indicam considerável profundidade cronológica (Lessa 2007). Na América do Sul, o caso mais antigo de decapitação é relatado para a região andina com ca. 3000 AP, no sítio Ásia 1 (Peru), e crânios individualizados foram descritos em Aguazuque, na Colômbia. Uma vez que quase todos os outros casos arqueológicos da América 
do Sul também ocorrem nos Andes (por exemplo, Nazca, Moche, Huari, Tiahuanaco), assumiu-se que a decapitação foi um fenômeno andino, tanto em suas origens bem como em suas expressões mais inequívocas.

Esta contribuição tem como objetivo apresentar uma versão em português da revisão da literatura originalmente publicada por Strauss e colaboradores em 2015, na qual são apresentadas as evidências disponíveis sobre a decapitação e a prática de individualização de crânios na América do Sul e apresentar novos casos de crânios individualizados, datados em torno de 9000-9500 cal BP (todas as faixas cronológicas aqui relatadas são baseadas em um intervalo de 95,4\%). Escavados no abrigo da Lapa do Santo, em Lagoa Santa (MG), tais casos de crânios individualizados incluem a decapitação mais antiga do Novo Mundo, implicando uma reavaliação da origem e da dispersão geográfica desse fenômeno no continente.

\section{Considerações terminológicas}

O termo "decapitação" será usado exclusivamente para se referir à prática de remover a cabeça do corpo antes da decomposição dos tecidos moles. A decapitação não precisa ser a causa da morte. $O$ processo de decapitação gera uma "cabeça decepada" e um "corpo decapitado". Alternativamente, quando a remoção do crânio ocorre após a total (ou quase total) decomposição dos tecidos moles (isto é, em contexto secundário post mortem) não se chama o processo de "decapitação", mas sim de "remoção do crânio". Analogamente, o esqueleto pós-craniano remanescente desse processo não pode ser referido como "decapitado".

A diferenciação no registro arqueológico desses dois tipos distintos de práticas passa principalmente pela análise do grau de articulação dos ossos e pela presença ou ausência de marcas de corte e marcas tafonômicas. De toda forma, nem sempre é possível ter certeza de qual processo ocorreu. Por isso, utiliza-se o termo "crânio individualizado" para se referir a todo crânio que não estava associado ao seu respectivo esqueleto, sem implicar procedimento específico que gerou tal individualização.

\section{Individualização de crânios e decapitação na América do Sul pré-colonial ${ }^{1}$}

A prática de decapitação na América do Sul está amplamente documentada pelas narrativas etnográficas e pela materialidade arqueológica. Os grupos tupinambás da costa brasileira são conhecidos por suas práticas antropofágicas (Castro 1992) e também por praticarem rituais nos quais partes do corpo humano (cabeças decapitadas incluídas) eram utilizadas como troféus de guerra (Petersen \& Crock 2007). Os índios arara, da Amazônia brasileira, realizavam a cerimônia do ieipari, na qual o crânio do inimigo derrotado era exibido no topo de uma haste ou utilizado como instrumento musical (Teixeira-Pinto 1997). Entre os uru-uru chipayas, na Bolívia, crânios foram usados como parte de uma liturgia cristã sincrética (Tung 2008). Entre os incas, a decapitação era um meio comum de estabelecer e reforçar as posições de status e poder. Em uma clara mensagem de supremacia militar, a cabeça de inimigos importantes era transformada em troféu e os crânios, em recipientes para líquidos (Ogburn 2007).

Os índios munduruku do rio Tapajós, que seguem se opondo de forma altiva aos avanços nefastos e inconstitucionais da agenda desenvolvimentista nacional (Pugliese \& Valle 2015), costumavam decapitar o inimigo derrotado imediatamente após a morte (Kruse 1934; Hartt 1881; Von Ihering 1907; Gabarain 1962; Leopoldi 2007; Menget 1993; Santos et al. 2007; Murphy 1957). O troféu era, então, trazido para a aldeia e ao longo de anos tornava-se foco de uma série de cerimônias (Leopoldi 2007; Santos et al. 2007). Para os munduruku, a cabeça dos inimigos derrotados servia claramente ao papel de troféu de guerra e

1 Esta seção apresenta uma versão traduzida e ligeiramente adaptada da revisão originalmente apresentada em inglês por Strauss et al., 2015. 
A prática de individualização de crânios e de decapitação na região de Lagoa Santa durante o Holoceno Inicial (Brasil) R. Museu Arq. Etn., 28: 86-108, 2017.

símbolo de superioridade bélica (Menget 1993; Murphy 1957; Von Ihering 1907). Ao mesmo tempo, a cabeça-troféu era um objeto capaz de aumentar o sucesso na caça, pois estava imbuída de uma semiologia feminina intrinsicamente associada com a fertilidade. No Equador, os jivaros produziam cabeças encolhidas (tsantsa) a partir dos inimigos mortos em combate (Sauvageau et al., 2009). As tsantsas tinham o poder de aprisionar a alma do inimigo morto, impedindo-o de perpetrar qualquer ato de vingança (Harner 1962; Rosaldo 1983; Taylor 1993; Steel 1999; ver Fausto \& Rodgers 1999, para uma perspectiva mais holística sobre o significado das tsantsas).

Alguns autores sugerem que a prática de caça de cabeças não era um fenômeno genuinamente indígena na América do Sul, mas sim o resultado da demanda comercial que os europeus criaram pelo seu conhecido apreço mórbido pelas cabeças-troféu (Ferguson 1990). No entanto, embora o mercado europeu certamente tenha intensificado a prática de caça às cabeças, levando a uma transformação das motivações que estavam por trás dela, evidências arqueológicas confirmam que práticas semelhantes eram comuns muito antes da chegada dos invasores ao Novo Mundo (Rubenstein 2007; Jandial et al. 2004). A seguir, será apresentada uma revisão da evidência arqueológica disponível na América do Sul sobre a prática de decapitação e individualização de crânios.

Os chimus (900 A.D.-1470 A.D.), no Peru, incorporaram a decapitação como um procedimento padrão em seus rituais de sacrifícios humanos. No complexo Huaca 1 , em Pacatnamu, os esqueletos mutilados de catorze indivíduos foram encontrados dentro de uma trincheira defensiva de três metros de profundidade. A presença exclusiva de jovens do sexo masculino, muitos dos quais foram amarrados e deixados expostos depois da morte, sugere que os indivíduos sacrificados eram guerreiros derrotados em combate. Esses indivíduos foram submetidos a diversos tipos de mutilação, incluindo decapitação (Verano 1986). Os chimus também realizaram sacrifícios humanos no Templo da Pedra
Sagrada, em Tucume (Toyne 2011). Estudos osteológicos sugerem uma sequência de procedimentos rituais, que começaria com a degola, seguida pela extração do coração e finalizada com a decapitação (um total de 72 indivíduos apresentava evidência osteológica explícita de que foram decapitados). As cabeças decepadas foram enterradas na mesma cova de seus respectivos corpos decapitados. A presença de crianças entre os indivíduos sacrificados torna improvável que estes fossem guerreiros derrotados, apontando para um tipo diferente de ritual de sacrifício em comparação a Pacatnamu. Crânios de adultos e crianças também foram usados como oferendas e incluídos em tumbas como objetos individualizados (envoltos em têxteis constituindo fardos funerários) que acompanhavam os restos mortais de pessoas sacrificadas (Giesela \& Hecker 1992).

Entre os chachapoyas da Amazônia peruana, crânios individualizados são encontrados no topo de elaborados sarcófagos antropomórficos que eram usados como monumentos funerários, como os de Karajía (Kauffman et al. 1989). Crânios decepados também foram encontrados na cidade murada de Kuelap. Em ambos os casos, análises osteológicas detalhadas não estão disponíveis, permitindo a existência de diversas linhas interpretativas, que incluem desde a possibilidade desses crânios serem o resultado de sacrifícios até a de serem simplesmente enterros tardios (Nystrom, Buikstra \& Muscutt 2010; DeNiro \& Epstein 1978).

Entre os huari (600 A.D.-1100 A.D.), no sul do Peru, cabeças decepadas foram transformadas em troféus e desempenharam um papel central em suas tradições ritualísticas (Tung 2007). Em Conchopata, pelo menos 31 cabeças-troféu foram recuperadas em "estruturas rituais" (EA143 e EA72) (Tung \& Knudson 2008). Os crânios apresentavam orifícios perto do bregma e, em alguns casos, no osso occipital (Tung 2008). O perfil demográfico das cabeças-troféu huari mostra uma predominância de indivíduos do sexo masculino de todas as idades, incluindo crianças (Tung \& Knudson 2008). Análises de isótopos de estrôncio sugerem uma origem não 
local para alguns dos indivíduos decapitados, e evidências osteológicas apontam para altos níveis de violência interpessoal (Tung \& Knudson 2010). A decapitação huari é entendida, portanto, como estratégia adotada pela elite para legitimar sua autoridade aos olhos dos inimigos. No entanto, nem todos os crânios individualizados encontrados em contextos huari eram cabeças-troféu. Na localidade de Huari, um crânio não modificado, enrolado em um pano e preso com quatro tupus de cobre foi encontrado sob o assoalho de uma construção arquitetônica, constituindo, provavelmente, uma oferenda (Verano 1995).

Durante o período de Tiahuanaco $(300$ A.D.-1000 A.D.), na bacia do lago Titicaca, na Bolivia, cenas envolvendo decapitação ou cabeças humanas decepadas eram um tema comum nas gravuras e esculturas de pedra tão características dessa cultura (Manzanilla \& Woodard 1990). O registro osteoarqueológico confirma que essas figurações refletiam práticas reais. No complexo residencial de Putuni, reservado às elites e localizado a oeste do sítio arqueológico Kalasasaya, um total de quinze indivíduos articulados e desarticulados foi enterrado como oferta dedicatória para o edifício, incluindo um crânio humano individualizado (Blom \& Janusek 2004; Couture \& Sampeck 2003).

Na pirâmide de Akapana, um sítio ritual no núcleo do complexo de Tiahuanaco, ossos humanos isolados ou esqueletos parcialmente articulados foram recuperados das bases de algumas das paredes da pirâmide. Vários crânios foram encontrados isolados (em um caso, três crânios estavam agrupados) e dezoito esqueletos não tinham os respectivos crânios (Manzanilla \& Woodard 1990). Pela ausência de marcas de corte, os crânios devem ter sido removidos em contextos secundários, o que tem sido interpretado como parte de um "culto esotérico às cabeças” (Blom \& Janusek 2004). $\mathrm{Na}$ localidade de Wata, cabeças humanas foram usadas como ofertas dedicatórias (Becker \& Alconini 2015). Três crânios decepados exibiam diferentes sinais de violência peri mortem, incluindo decapitação, fratura craniana e facial, descarnamento, remoção da mandíbula e extração dos olhos. A extrema violência que é caracterizada por esses resultados sugere que isso foi feito para remover a "energia simbólica" dessas pessoas e legitimar a autoridade da crescente presença de Tiahuanaco na região (Becker \& Alconini 2015).

A prática de remoção de cabeças é um tema comum na iconografia moche (100 A.D.700 A.D.), no norte do Peru (Donnan \& McClelland 1979; Cordy-Collins 1992; CordyCollins 2001; Donnan 1995). A evidência arqueológica e osteológica confirma se tratar de uma prática real e não meramente figurativa. Na Plaza 3A e na Plaza 3C, de Huaca de la Luna (Bourget 1998, 2001; Verano 1995, 1998, 2001a, 2001b, 2008a, 2008b; Verano et al. 1999), cabeças decepadas e corpos decapitados foram encontrados em um contexto de sacrifício generalizado de guerreiros derrotados (Sutter \& Cortez 2005; Verano 2000, 2008a). Na Plaza $3 \mathrm{C}$, além do ritual do sacrifício, os crânios decepados foram também objeto de manipulação intencional (tanto peri mortem como post mortem) e, possivelmente, de alguma forma de canibalismo ritual (Verano 2008a). Perto dali, no complexo chamado ZUM 8, dois crânios decepados foram alterados para funcionar como recipientes de algum tipo de líquido. Isso explicita a diversidade de propósitos a que se prestava a prática da remoção de cabeças entre os moche, que ia além das necessidades imediatas de sacrificar guerreiros derrotados (Verano et al. 1999; Verano 1998).

Na Huaca Dos Cabezas foi encontrado um conjunto de dezoito crânios decepados com marcas de corte na parte anterior das vértebras cervicais (Cordy-Collins 2001). Perto dali, foi encontrado o esqueleto completo de um homem alto que tinha um tumi (machado cerimonial caracterizado por uma lâmina metálica semicircular) em sua mão esquerda e, em sua mão direita, uma reprodução feita em cerâmica de uma cabeça humana. Acredita-se que esse indivíduo exercia em vida o papel de um decapitador ritual. Em San José del Moro (túmulo M-U1221), sete pessoas foram enterradas juntas, e oito crânios decepados foram colocados por cima do enterro (Butters 2005). A presença de vários artefatos de 
A prática de individualização de crânios e de decapitação na região de Lagoa Santa durante o Holoceno Inicial (Brasil) R. Museu Arq. Etn., 28: 86-108, 2017.

cerâmica relacionados a atividades xamânicas (Carlos 2004) sugere que os crânios são oferendas fúnebres, possivelmente imbuídas de algum tipo de poder sobrenatural.

Durante o período moche, ossos humanos de túmulos reabertos foram usados como oferendas dedicatórias. Os crânios eram a parte anatômica mais comumente selecionada e, portanto, nem todos os crânios individualizados ou corpos sem cabeça são um produto da prática de decapitação (ou seja, a remoção peri mortem da cabeça) (Nelson 1998; Millaire 2004). Além de cabeças humanas, entre os moche também é comum encontrar cabeças decepadas de lhamas como parte de oferendas funerárias (por exemplo, Huaca Rajada Sipán (Alva 1994) e Tumba 2 de Huaca Dos Cabezas (Donnan 2001, 2007)). Durante o período gallinazo, que antecede os moche no norte do Peru, no sítio Huacas de Moche, um único caso de remoção do crânio é conhecido (enterro G2). O crânio foi removido e substituído por uma jarra de cerâmica com a figura de uma cabeça humana "carimbada" nela. Não é possível, no entanto, determinar se essa foi uma remoção peri mortem ou post mortem (Donnan \& Mackey 1978).

Os nazca (100 a.C.-800 A.D.), localizados na costa sul do Peru, produziam elaboradas cabeças-troféu que eram caracterizadas por um orifício na parte frontal da cabeça e um alargamento do forame magno (Baraybar 1987; Coelho 1972; Drusini \& Baraybar 1991; Proulx 1971, 1989, 1999, 2001). Os lábios e os olhos eram normalmente selados com espinhos e a cabeça estava equipada com uma alça de transporte (Verano 1995). A iconografia disponível e a predominância de homens adultos entre os casos de decapitação (Verano 1995) indicam que esta deve ter ocorrido no campo de batalha e que a cabeça decepada funcionava como um troféu de guerra. Análises isotópicas sugerem que ocorriam batalhas dentro do próprio vale de Nazca, envolvendo guerreiros locais (Knudson et al. 2009; Conlee et al. 2009). As cabeças eram comumente enterradas em conjuntos que variavam de 3 a 40 ou mais (Browne, Silverman \& Garcia 1993; Proulx 1989). Portanto, a importância das cabeças decepadas foi muito além da sinalização de supremacia militar e presume-se que elas eram um elemento central nos rituais, cujo objetivo era controlar as forças da natureza, em especial no que se refere à fertilidade da colheita (Proulx 2001; Carmichael 1995; Conlee 2007; DeLeonardis 2000).

Na localidade de Chavín de Huantar (1200 a.C-500 d.C.), no planalto do norte do Peru, quatro crânios individualizados foram encontrados em uma plataforma ritual (fase Urabarriu, 900 a.C.-500 d.C.). Uma vez que os crânios eram de um ancião, de um adulto jovem, de uma adolescente e de uma criança, o conjunto é considerado como pertencente a uma família estendida (Burger 1984). Os crânios não mostram sinais de modificação. Outro crânio isolado em Chavín de Huantar foi recuperado na Galeria das Oferendas e, embora não haja uma data precisa, ele pode representar a mais antiga cabeça-troféu encontrada nos Andes (Reichlen 1973; Tung 2007).

Durante o período formativo, cinco crânios decepados foram encontrados na localidade de Wichquana, no Peru. Enterrados em poços, dentro de uma estrutura cerimonial, esses crânios tinham as vértebras cervicais articuladas a eles, sugerindo que foram decapitados enquanto os tecidos moles ainda estavam presentes. Possivelmente, eles são o resultado final de algum tipo de ritual de sacrifício (Lumbreras 1981). O sítio Ásia 1 (Engel 1963), na costa do Peru central, é geralmente considerado como o mais antigo caso de uma possível decapitação na América do Sul (ca. 3000 BP) (Verano 1998; Tung 2007). No entanto, na ausência de uma descrição osteológica detalhada, não é possível determinar se esse caso é de fato uma decapitação.

Os achados em Ásia 1 consistem em três pacotes embrulhados, contendo um total de oito crânios individualizados encontrados em covas separadas. Além disso, dois esqueletos sem seus crânios também estavam presentes. Um crânio dos pacotes tinha marcas de corte no osso frontal, que foram interpretadas como resultantes da retirada do escalpo da face (Engel 1963). O contexto funerário incluiu vários tecidos, um colar de discos de osso, pingentes, um pino feito de osso, penas, pigmento vermelho 
e um espelho (Engel 1963). Tal tratamento elaborado indica que a prática de remoção de crânios no sítio Ásia 1 poderia ter sido reservada a indivíduos de status especial. Na ausência de modificações adicionais, é provável que não se trate de cabeças-troféu, mas oferendas relacionadas à veneração ancestral (Verano 1995).

O sítio Ásia 1 é comumente citado como a primeira aparição de cabeças decepadas no registro arqueológico sul-americano. No entanto, o sítio de Aguazuque (5025-2725 BP) pode ser um candidato ainda mais antigo. Localizado em Savana de Bogotá, Colômbia, foram identificados pelo menos dois casos de crânios decepados e um corpo sem cabeça em um total de 59 enterros. O sítio apresenta um dos registros funerários mais elaborados do período arcaico, e a remoção dos crânios era parte de um contexto mortuário mais amplo, que estava centrado na manipulação dos ossos e de partes do corpo (Neves, Hubbe \& Correal 2007; Santoro et al. 2005; Correal 1990; Strauss et al. 2015). Os ossos longos, por exemplo, foram seccionados transversalmente, separando diáfises e extremidades, e pintados com motivos geométricos. Mais uma vez, na ausência de uma descrição osteológica detalhada descrevendo a presença ou ausência de marcas de corte, não é possível determinar se os crânios individualizados de Aguazuque representam verdadeiros casos de decapitações. Não obstante, o fato de que um dos crânios estava articulado com as vértebras cervicais é altamente sugestivo de que a remoção ocorreu enquanto tecidos moles ainda estavam presentes.

No Brasil, até onde foi possível determinar, existe apenas um único caso descrito de uma possível decapitação no período pré-colonial. Essa constatação vem do sambaqui do forte Marechal Luz (Bryan 1993), mas não há descrições osteológicas ou cronologia associada ${ }^{2}$. Assim, a partir da revisão apresentada aqui fica claro que quase todos os casos arqueológicos de decapitação ou de cabeças decepadas na América do Sul estão concentrados na região dos Andes (Arnold 2008). Por essa razão, é comumente assumido que esse era um

2 Verônica Wesolowski, comunicação pessoal fenômeno andino (Ferguson 1990; CordyCollins 1992; Jandial et al. 2004; Conlee 2007). Entretanto, o estudo dos sepultamentos exumados da Lapa do Santo, em Minas Gerais, mostra que esse cenário é antes fruto de um viés de visibilidade arqueológica do que um reflexo fiel das práticas funerárias na América do Sul durante o Holoceno Inicial.

\section{Os crânios individualizados da Lapa do Santo}

O sítio arqueológico da Lapa do Santo está localizado na área de proteção ambiental (APA) Carste de Lagoa Santa, no município de Matozinhos, em Minas Gerais. A região fica situada a cerca de $50 \mathrm{~km}$ ao norte de Belo Horizonte (vide Strauss 2010 para mapa com localização do sítio). A Lapa do Santo (Fig. 1) é uma caverna que se projeta para dentro de um enorme paredão calcário com aproximadamente 30 metros de altura, cuja entrada apresenta ampla área abrigada com cerca de $1300 \mathrm{~m}^{2}$. Entre 2001 e 2009 o sítio foi escavado no âmbito do projeto de pesquisa temático Fapesp "Origens e microevolução do homem na América”, coordenado por Walter Neves, da Universidade de São Paulo (USP). A partir de 2011, uma nova área de escavação (que não aparece na Fig. 1) foi estabelecida como parte do projeto "As práticas mortuárias dos primeiros americanos", coordenado pelos autores deste artigo com apoio institucional do Laboratório de Estudos Evolutivos Humanos do Instituto de Biociências (IB) da USP e financiamento do Instituto Max Planck de Antropologia Evolutiva. Até o momento, catorze sepultamentos foram encontrados como parte dessa nova área de escavação, mas eles não serão considerados nesta contribuição.

Nas etapas iniciais de escavação, sondagens foram feitas ao longo de praticamente toda a extensão da área abrigada, no intuito de avaliar o potencial do sítio. Durante esse processo ficou bem caracterizado que a região sul do abrigo apresentava um pacote potencialmente intacto com idades que remetiam ao Holoceno Inicial. A partir de então, essa parte do sítio se tornou a área principal de escavação, e uma 
A prática de individualização de crânios e de decapitação na região de Lagoa Santa durante o Holoceno Inicial (Brasil) R. Museu Arq. Etn., 28: 86-108, 2017.

superfície ampla passou a ser escavada através da décapage de níveis naturais. Do ponto de vista da arqueologia das práticas mortuárias, a escolha dessa área do sítio se mostrou muito acertada, já que nela foram encontrados 26 sepultamentos datados do Holoceno Inicial e que estavam, em sua maioria, em ótimo estado de conservação (vide Strauss et al. 2016 para detalhes sobre a cronologia dos sepultamentos e Villagran et al. 2017 para estudo de processos de formação do sítio). Conforme será detalhado na sequência, cinco desses sepultamentos incluíam ou eram constituídos por crânios individualizados.

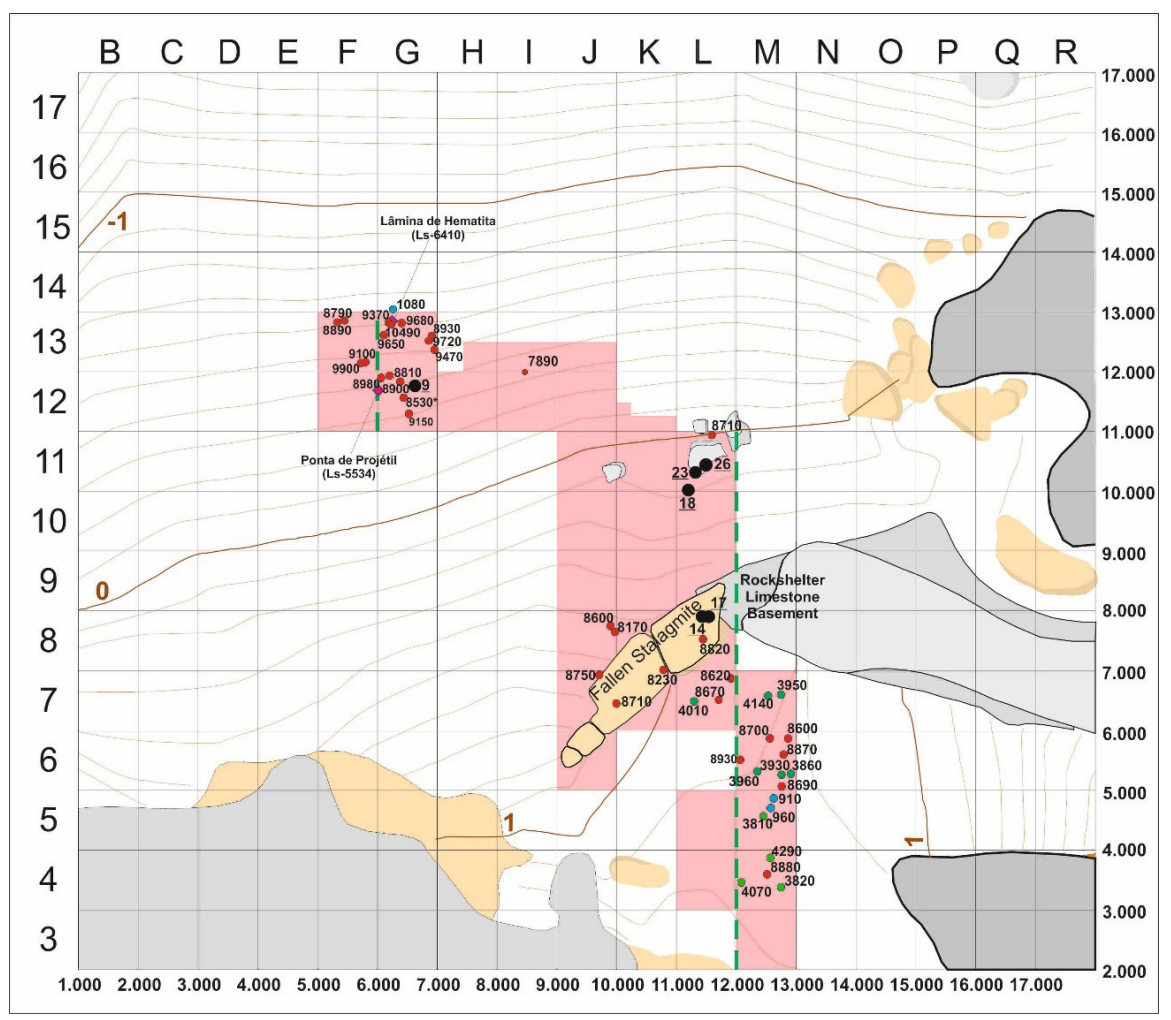

Fig. 1. Croqui da área principal de escavação da Lapa do Santo com a distribuição horizontal das amostras de carvão datadas e dos sepultamentos humanos discutidos no texto. Cada círculo pequeno representa uma amostra de carvão e o número associado é a datação radiocarbônica correspondente (não calibrada). Círculos vermelhos, verdes e azuis correspondem, respectivamente, a carvões do Holoceno Inicial, Médio e Final. Os círculos maiores e pretos indicam a localização dos sepultamentos discutidos no texto. As áreas sombreadas em vermelho claro, bege e cinza indicam, respectivamente, unidades escavadas, espeleotemas e rocha da base do abrigo.

Fonte: Autor.

O Sepultamento 9 é composto por um único indivíduo subadulto, do qual estavam presentes crânio, mandíbula, poucos fragmentos de costelas e partes da bacia. O neurocrânio foi encontrado repousando sobre o lado esquerdo, com a face ligeiramente inclinada para baixo e voltada para o norte (Fig. 2). O neurocrânio estava completamente preenchido por sedimento. Os demais ossos estavam próximos ao neurocrânio. Os ossos da bacia, o temporal e a mandíbula estavam unidos por concreção carbonática. Ainda que apenas o neurocrânio 
tenha se preservado integralmente, os ossos do maxilar, os da base do crânio e a mandíbula também estavam presentes. Os alvéolos da mandíbula e das maxilas estavam vazios, com exceção dos primeiros molares permanentes e de alguns germes de dentes permanentes que não haviam erupcionado no momento da morte.

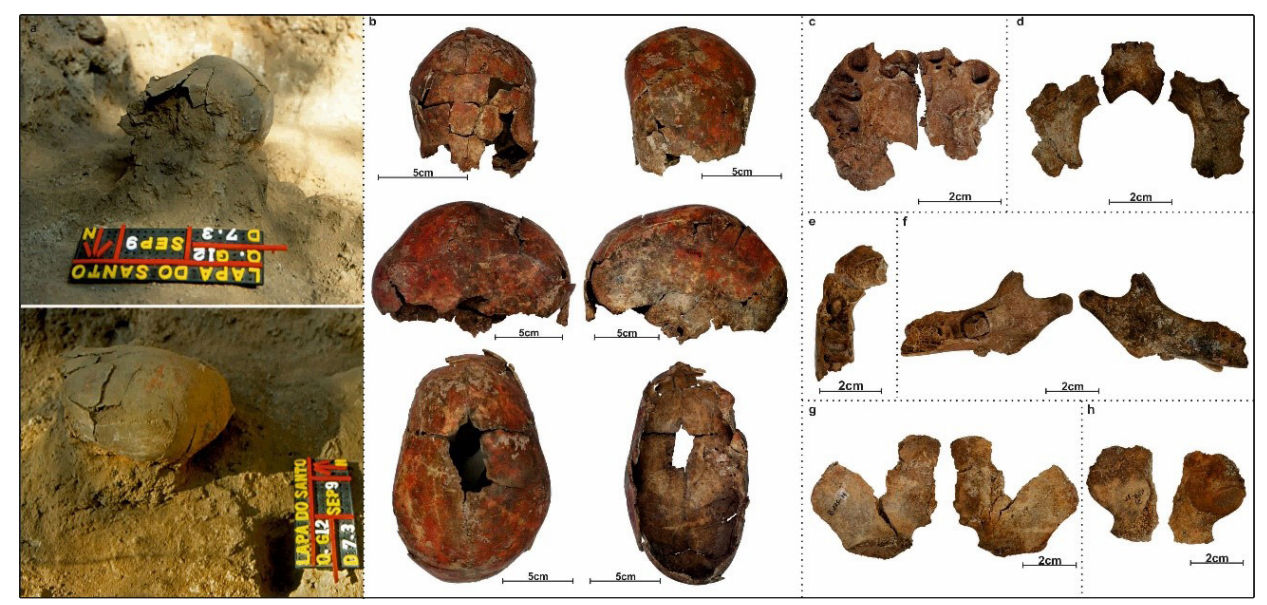

Fig. 2. Sepultamento 9 da Lapa do Santo. a) Na foto de campo é possível observar o crânio individualizado de um indivíduo subadulto. b) Crânio visto a partir das seis normas básicas. c) Vista inferior das maxilas. Os alvéolos estavam vazios e os dentes correspondentes não foram encontrados. d) Ossos não fusionados do basicrânio. e) Vista superior do hemiarco esquerdo mandibular. f) Vista lingual e labial do hemiarco direito mandibular. Repare que o primeiro molar ainda não erupcionou. g) Ílio esquerdo. h) Ílio direito.

Fonte: Autor.

Os ílios esquerdo e direito de um indivíduo subadulto foram encontrados próximos ao neurocrânio. $O$ tamanho da pélvis e do crânio torna provável que tais ossos e o crânio pertençam a um mesmo indivíduo. A ausência dos demais ossos desse indivíduo sugere que a preparação do corpo - nesse caso, a separação da cabeça e a possível introdução dos ossos da bacia dentro desta - ocorreu em momento distinto ao do enterramento inicial. Além disso, o crânio apresenta coloração avermelhada e em algumas regiões havia uma fina camada de pó vermelho recobrindo o osso, resultado da aplicação de pigmento vermelho.

O Sepultamento 14 é composto por um crânio individualizado de um adulto e pelos ossos de pelo menos outros dois indivíduos subadultos (Fig. 3). A face e algumas regiões do basicrânio não estavam presentes, mesmo o crânio apresentando excelentes condições de preservação. Manchas avermelhadas, seguramente decorrentes da aplicação de pigmento vermelho, foram identificadas na parte basal e lateral das porções mais anteriores do crânio. Essas manchas são particularmente intensas na superfície superior das órbitas e nas fossas temporais. Não foram identificadas marcas de queima ou corte no crânio. $\mathrm{O}$ eixo násio-opistocrânio estava orientado no sentido noroeste-sudeste. A base do crânio estava para baixo, e o crânio estava preenchido por sedimentos.

Ao lado do crânio foi colocado um fardo de ossos constituído exclusivamente por peças ósseas do pós-crânio de subadultos (Fig. 3). Faziam parte do fardo ossos longos, ossos da bacia, escápula, clavícula, costelas e ossos de pé e/ou mão. ${ }^{3}$ Esse fardo estava colocado por cima e ao lado direito do crânio. As extremidades desse fardo estavam delimitadas pelas duas

3 Devido ao tamanho diminuto dos ossos, não foi possível determinar se eram ossos de pé ou mão. 
A prática de individualização de crânios e de decapitação na região de Lagoa Santa durante o Holoceno Inicial (Brasil) R. Museu Arq. Etn., 28: 86-108, 2017.

pélvis da criança mais velha. As costelas foram colocadas por cima dos ossos longos.

A partir do comprimento dos ossos longos foi possível determinar que pelo menos dois indivíduos subadultos estavam representados, com idades aproximadas de um e três anos. $\mathrm{O}$ indivíduo com cerca de um ano estava representado pelos seguintes ossos: rádio direito, úmero esquerdo, extremidade proximal do úmero direito, tíbia esquerda, tíbia direita, fíbula direita, fêmur esquerdo, escápula esquerda, ílio esquerdo, púbis esquerdo e ísquio direito. $\mathrm{O}$ indivíduo com cerca de três anos estava representado pelos seguintes ossos: rádio esquerdo, ulna esquerda, epífise proximal de fêmur esquerdo, escápula direita, escápula esquerda, ílio esquerdo, ílio direito, ísquio esquerdo, ísquio direito e púbis esquerdo. Possivelmente, os ossos de mão e pé que foram encontrados pertencem ao indivíduo com cerca de um ano de idade.

Dentre os ossos longos que faziam parte do fardo, dois consistem em extremidades cujas diáfises foram removidas, seis consistem em diáfises cujas extremidades foram removidas e dois são ossos inteiros sem nenhum sinal de manipulação (Fig. 4). Nenhuma das epífises não fusionadas estava presente nesse fardo de ossos.

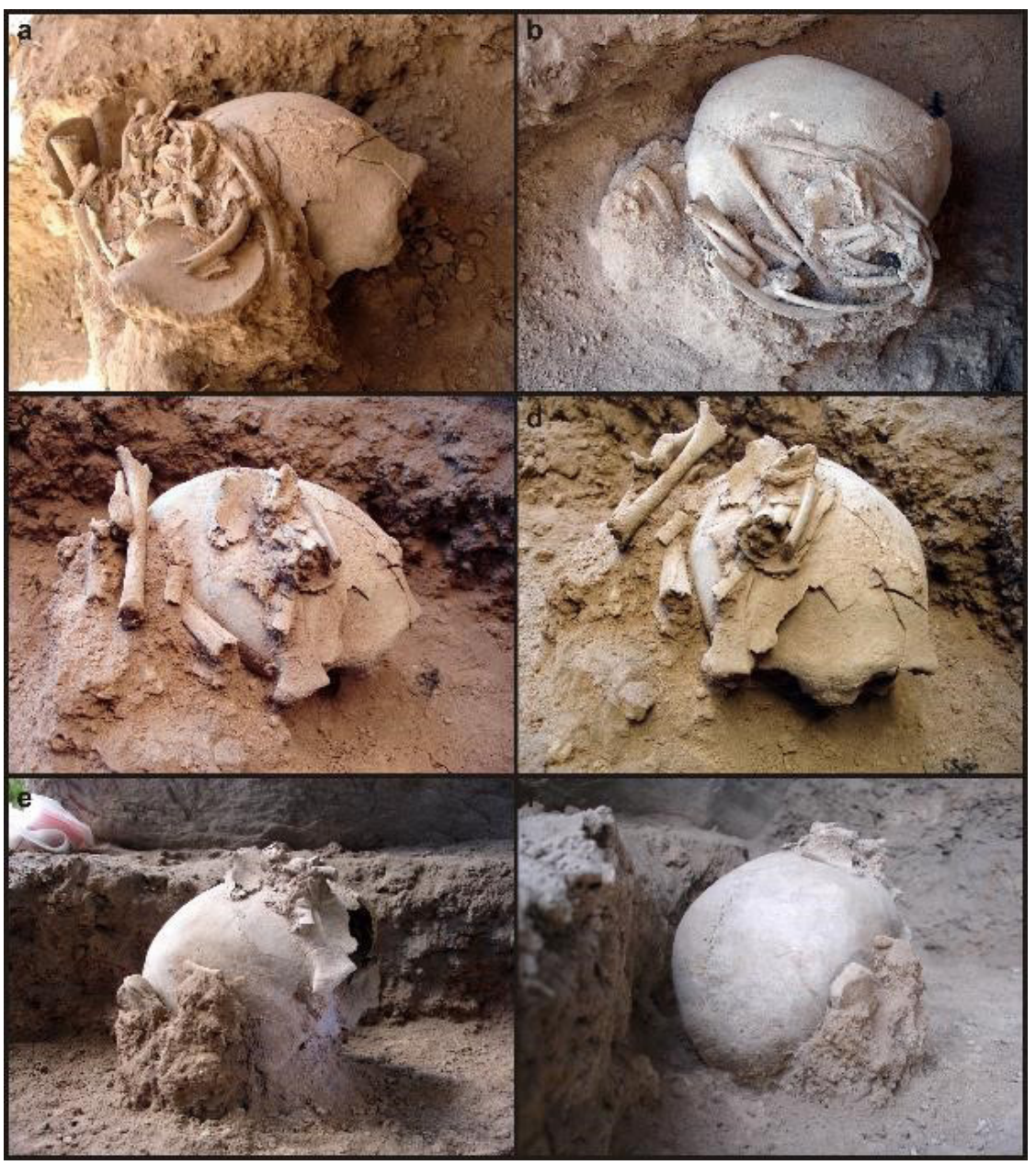

Fig. 3. Sepultamento 14 da Lapa do Santo. Sequência mostrando as etapas consecutivas do processo de exumação.

Fonte: Autor. 


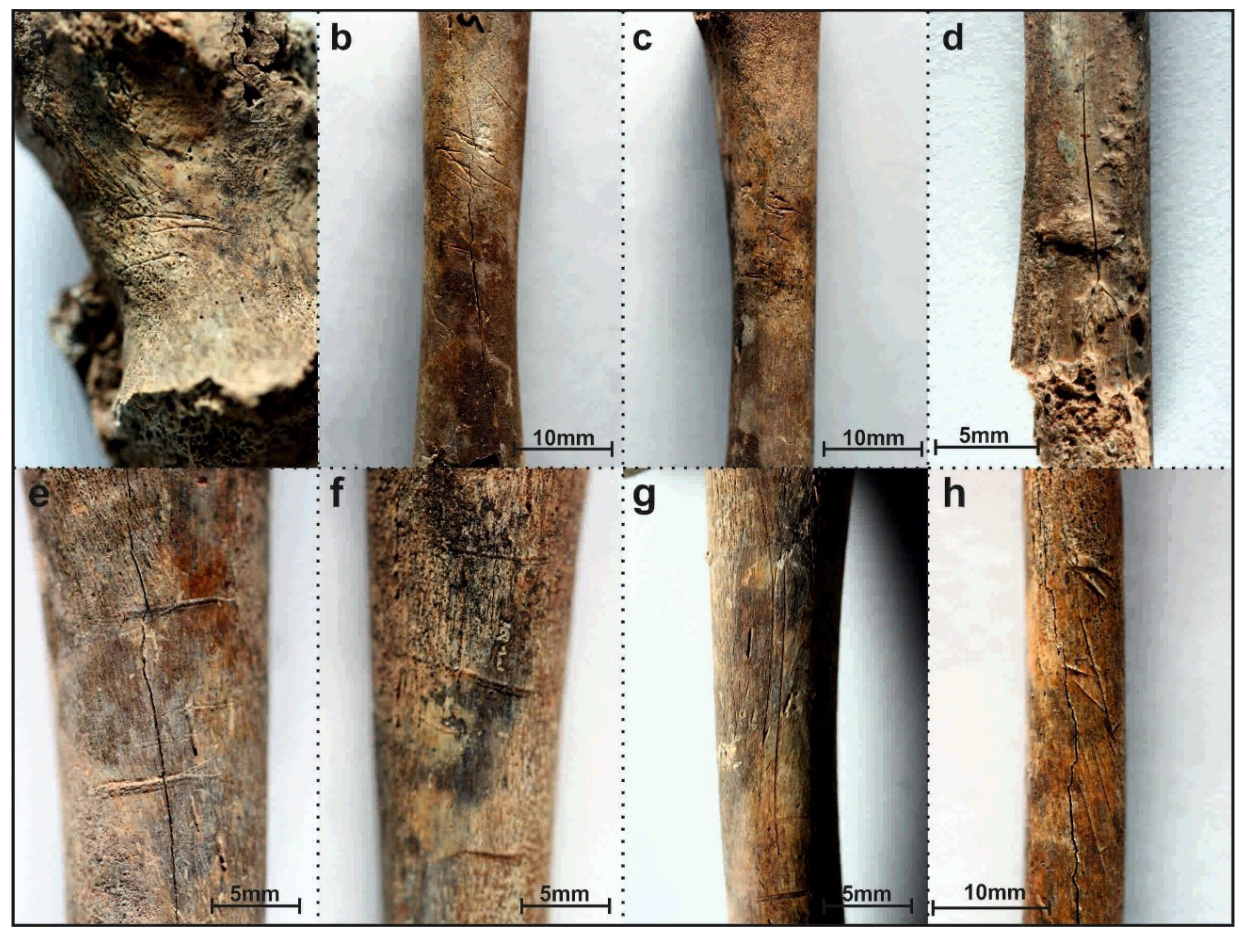

Fig. 4. Sepultamento 14. Fotos das incisões e marcas de impacto presentes nos ossos longos de indivíduos subadultos que faziam parte do fardo de ossos depositado sobre o crânio adulto individualizado. Em todas as fotos a extremidade distal encontra-se na parte inferior da imagem. a) Extremidade proximal do fêmur esquerdo. b) e c) Vista anterior e lateral do fêmur esquerdo. d) vista posterior da diáfise do rádio direito. e) Vista medial da tíbia esquerda. f) Vista medial da parte proximal da tíbia direita. g) Vista posterior da parte proximal da tíbia direita. h) Diáfise da fíbula direita.

Fonte: Autor.

O Sepultamento 17 é composto por um crânio individualizado adulto, preenchido com ossos cortados de um indivíduo também adulto e por um conjunto de ossos pós-cranianos de uma criança que foram colocados ao lado do crânio (Fig. 5). O crânio estava quase completo, mas as regiões temporais e basais bastante fragmentadas. Entre os ossos que foram encontrados dentro do crânio, foi possível distinguir aqueles que faziam parte do próprio crânio e ossos de outras regiões anatômicas. Na primeira categoria estão fragmentos do temporal, do parietal, da face, das maxilas e da mandíbula.

Tanto as maxilas como a mandíbula não apresentavam nenhum dente, com exceção das raízes do primeiro e do segundo molar inferior direito, que permaneceram no alvéolo (Fig. 6). Na medida em que todos os alvéolos estão preservados, não se trata de perda em vida dos dentes. Além disso, como nenhum dente foi encontrado junto ao sepultamento ou próximo a ele, sua ausência não pode ser atribuída a processos pós-deposicionais. Portanto, ou os dentes foram intencionalmente removidos ou caíram durante um suposto período em que o crânio teria sido manuseado após a decomposição dos tecidos moles.

As regiões basais do crânio, representadas por fragmentos e pela margem alveolar externa do maxilar, e a mandíbula apresentavam regiões escurecidas indicativas de queima. No caso da mandíbula e das maxilas, apenas a parte exterior da margem alveolar foi queimada, particularmente a região compreendida entre os 
A prática de individualização de crânios e de decapitação na região de Lagoa Santa durante o Holoceno Inicial (Brasil) R. Museu Arq. Etn., 28: 86-108, 2017.

dois primeiros pré-molares. Além disso, nem o palato nem o interior dos alvéolos apresentam sinais de queima. Tal configuração indica que o evento de queima ocorreu enquanto esse indivíduo ainda tinha os dentes, impedindo que a queima afetasse a parte interna dos alvéolos. Mais do que isso, a distribuição espacial das áreas afetadas pelo calor sugere que os tecidos moles ainda estavam presentes no momento da queima.

Dentro do crânio também foram encontrados uma extremidade distal do úmero esquerdo, uma extremidade proximal de ulna esquerda, uma clavícula esquerda e uma direita, ossos da mão, uma escápula esquerda e fragmentos de ossos longos. Todos esses ossos eram de um indivíduo adulto. Uma vez que o rádio e a ulna se articulam perfeitamente, não resta dúvida de que pertenciam ao mesmo indivíduo. Com relação aos demais ossos, ainda que seja impossível ter certeza, assume-se que também pertenciam ao mesmo indivíduo. Os ossos longos, em particular, apresentavam clara evidência de manipulação na forma de marcas de corte e queima.

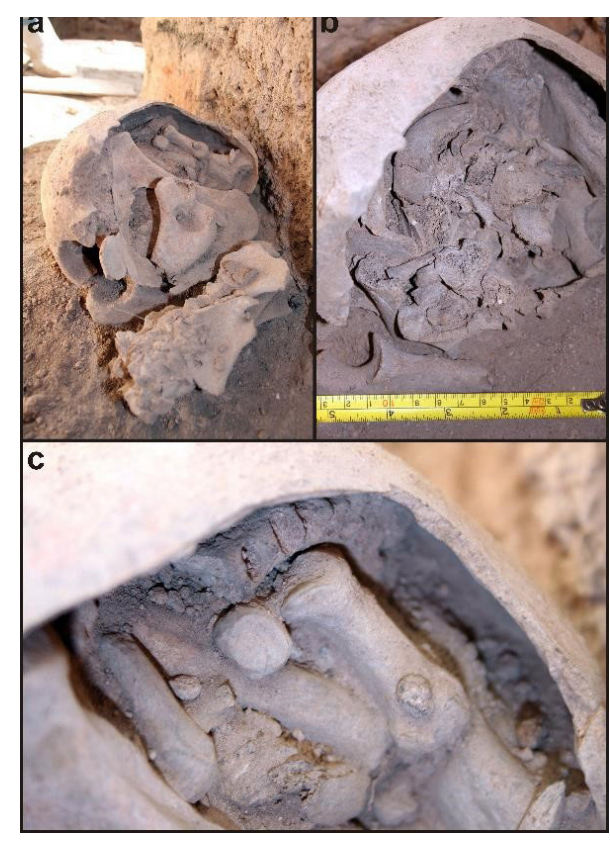

Fig. 5. Sepultamento 17 da Lapa do Santo. Na foto de campo é possível observar o crânio adulto individualizado e ao seu lado direito, o fardo de ossos de subadultos.

Fonte: Autor.
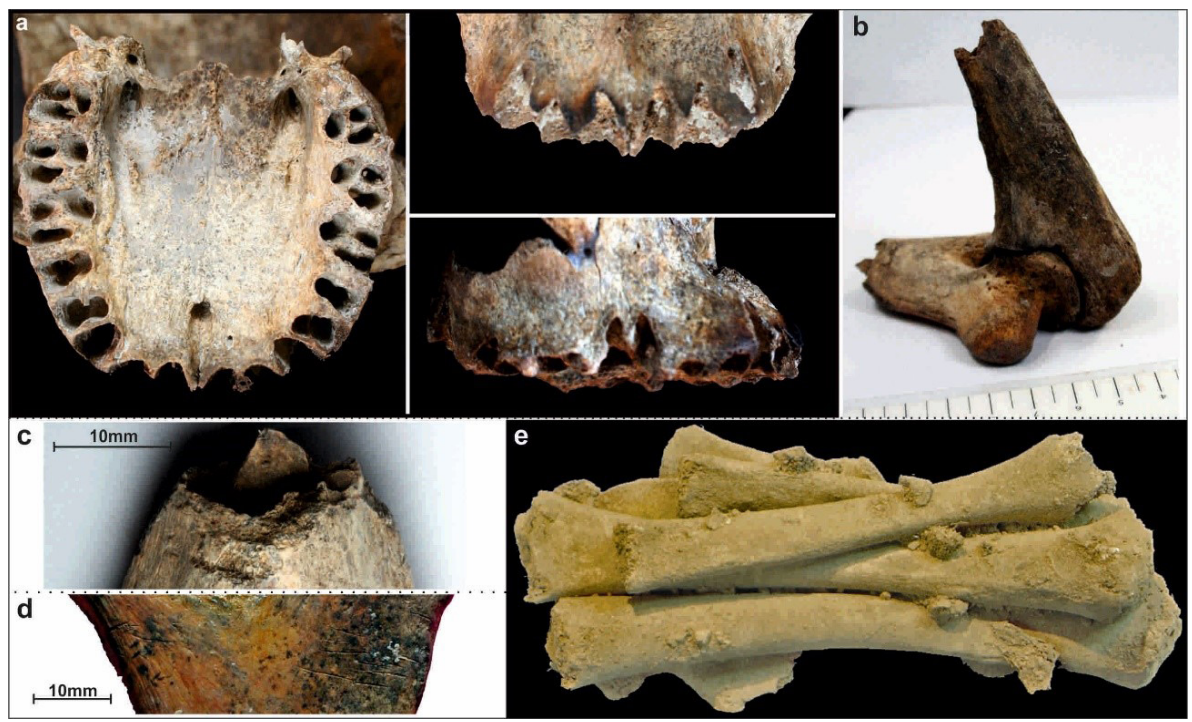

Fig. 6. Sepultamento 17 da Lapa do Santo. a) Detalhe da ausência de dentes e marca de queima na face bucal da maxila. b) Ulna e úmero seccionados em articulação. c) Detalhe da margem seccionada apresentando característica morfologia biselada. d) Detalhe das marcas de descarnamento. e) Vista do fardo de ossos longos (ca. $15 \mathrm{~cm}$ de comprimento) antes de seu desmonte em laboratório.

Fonte: Autor. 
O Sepultamento 18 é constituído por ossos não articulados de, no mínimo, um adulto e uma criança (Fig. 7). Os ossos não estavam dentro de uma cova, ou pelo menos os limites desta não foram reconhecidos. $\mathrm{O}$ indivíduo adulto está representado pelos dois úmeros, pelo rádio direito e por um fragmento de diáfise de osso longo, que, possivelmente, é um fêmur. Há também um único incisivo central de um indivíduo adulto que foi encontrado próximo aos outros ossos, embora seja impossivel determinar se ele é do mesmo indivíduo representado pelos ossos longos (ou se de fato faz parte desse sepultamento). Já a criança está representada por uma mandíbula muito bem preservada, por dois ossos temporais e por um occipital quase inteiro.

Os ossos longos estavam dispostos num feixe, paralelos entre si. O eixo do feixe encontrava-se, grosso modo, orientado no sentido norte-sul. Esse feixe de ossos longos encontravase diretamente sobre a mandíbula da criança. Esta última estava em posição vertical, com a parte anterior para baixo e os côndilos para cima. Formava, assim, uma espécie de arco ("U") sobre o qual o feixe de ossos longos estava encaixado. Todos os ossos longos estavam unidos por concreção (Fig. 7).

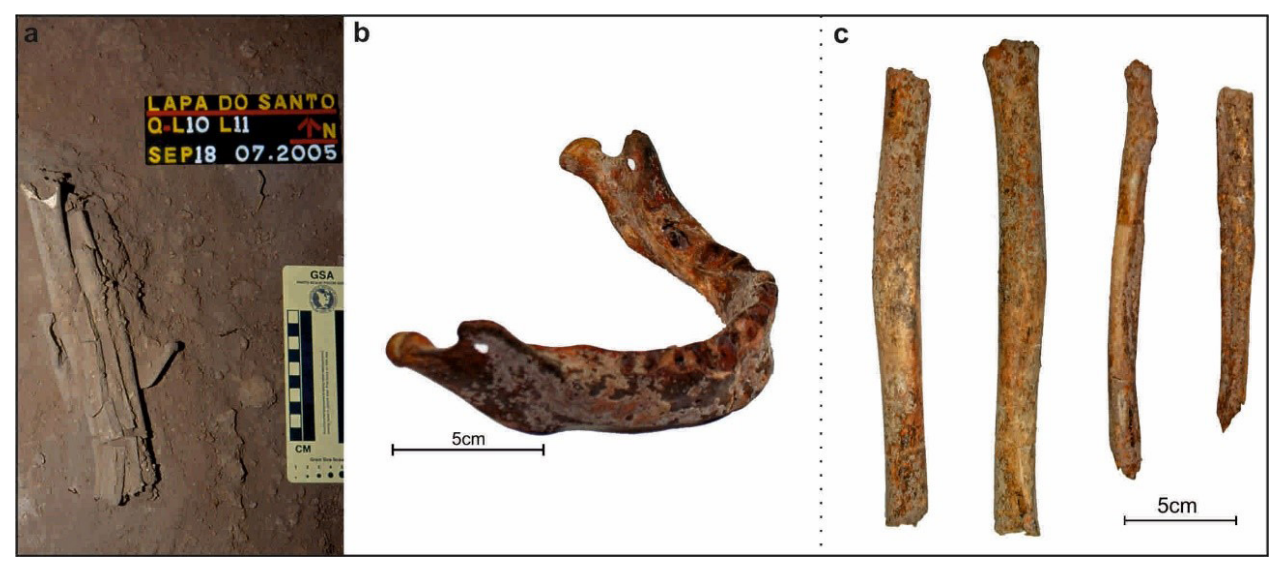

Fig. 7. Sepultamento 18 da Lapa do Santo. Na foto de campo é possível observar o feixe de ossos longos de um indivíduo adulto que foi depositado dentro da mandíbula de um indivíduo subadulto.

Fonte: Autor.

Os ossos que constituem o feixe foram manipulados de diversas formas. Os ossos longos apresentam suas extremidades cortadas. A mandíbula também foi manipulada. Em cada processo coronoide há um pequeno orifício de formato circular com cerca de 3 milímetros de diâmetro. Parece pouco provável que esses orifícios tenham tido outra função que não a de passar algum tipo de cordão por deles. Existem três razões que sustentam essa interpretação. Em primeiro lugar, a posição desses orifícios é absolutamente simétrica, diminuindo as chances de que tenham sido produzidos por agentes naturais pós-deposicionais. Em segundo lugar, a margem desses orifícios é arredondada.
Em terceiro lugar, o contexto arqueológico favorece essa interpretação, pois essa mandíbula estava associada a um conjunto de ossos que nitidamente foi manipulado (isto é, houve extração de extremidades dos ossos longos). Sugere-se que essa mandíbula funcionou como uma "fivela" que manteve juntos os ossos longos na disposição de feixe. Assim, por esses dois orifícios passava alguma espécie de cordão que fechava a parte "aberta" da mandíbula, fazendo com que os ossos longos permanecessem juntos.

Por fim, a mandíbula não tinha nenhum dente em seus alvéolos, tampouco foram encontrados dentes compativeis nas proximidades. Ainda que seja 
A prática de individualização de crânios e de decapitação na região de Lagoa Santa durante o Holoceno Inicial (Brasil) R. Museu Arq. Etn., 28: 86-108, 2017.

impossivel determinar se esses dentes foram intencionalmente arrancados ou se caíram durante o manuseio da mandíbula, a primeira opção parece bastante provável. Afinal, a prática de extração de dentes post mortem é bem documentada no sítio (vide Sepultamento 17). Inclusive, entre os 84 dentes do Sepultamento 23, 38 eram decíduos. ${ }^{4}$

O Sepultamento 23 era composto por uma calota craniana incompleta de um indivíduo subadulto, na qual estavam presentes o occipital e o parietal esquerdo. Junto dela foram encontrados um rádio direito, uma extremidade proximal de ulna e um fragmento de diáfise com cerca de 3 centímetros, que foi nitidamente cortado em suas duas extremidades, além de fragmentos de costela, fragmentos de vértebras e 84 dentes. Todos os ossos encontravam-se dentro da calota craniana. Esta, por sua vez, apresenta tonalidades avermelhadas indicativas da aplicação de pigmento vermelho.

Entre os 84 dentes presentes, 48 eram permanentes e 38 eram decíduos. A partir de critérios como quantidade de dentes presentes, simetria, tamanho e grau de desgaste, foi possivel determinar que os dentes permanentes representavam dois indivíduos adultos.

Os dentes permanentes foram os únicos elementos anatômicos de adultos presentes no Sepultamento 23. Já os dentes decíduos parecem representar um mínimo de três indivíduos devido à presença de cinco incisivos centrais superiores. Assim, pelo menos cinco indivíduos estão representados no sepultamento.

O Sepultamento 26 é constituído pelos remanescentes de um único indivíduo adulto, do sexo masculino (vide Strauss et al. 2015 para uma descrição mais detalhada desse sepultamento). Os ossos encontravam-se articulados e em posição anatômica. Estavam presentes o crânio, a mandíbula, as seis primeiras vértebras cervicais, todos os ossos da mão direita, quase a totalidade dos ossos da mão esquerda e a extremidade distal do rádio esquerdo. Esses elementos estavam dispostos

4 Foi verificado em laboratório que nenhum dos dentes decíduos do Sepultamento 23 são oriundos da mandíbula do Sepultamento 18. da seguinte maneira: o crânio e a mandíbula estavam perfeitamente articulados e com as maxilas (boca fechada); as seis vértebras cervicais estavam articuladas entre si e com a base do crânio; a coluna cervical estava dobrada para a frente, em direção à boca do indivíduo. Isso reflete o fato de o crânio estar com a face inclinada para cima e apoiado sobre seu pescoço e nuca. Esse conjunto plenamente articulado representa uma cabeça que foi amputada. $\mathrm{O}$ hioide não foi encontrado.

Também estavam presentes duas mãos amputadas. Ambas foram colocadas sobre a região frontal (anterior) com as palmas voltadas para o crânio. A mão direita estava sobre o lado esquerdo do crânio, com os dedos voltados para cima (sobre o parietal) e o pulso para baixo (sobre a órbita). A mão esquerda encontravase em posição oposta, colocada sobre o lado direito do crânio, com o pulso sobre a região parietal e os dedos sobre a face. Com exceção do primeiro metacarpo e de uma falange da mão esquerda, todos os ossos das duas mãos foram recuperados.

Além dos ossos das mãos, foi identificada a extremidade distal do rádio direito. Esse osso foi nitidamente seccionado. A secção transversal resultante desse processo é consideravelmente plana e perpendicular ao eixo longo do osso. A borda gerada pela amputação é picotada, apresentando um adelgaçamento do osso cortical. $\mathrm{Na}$ face lateral há uma incisão de 3 milímetros de comprimento e 1 milímetro de largura, cuja orientação é concordante com o plano de amputação do membro, que se encontra próximo dessa incisão. Isso parece indicar que esta é antes resultado de um gesto mal calculado, cujo objetivo era o corte do osso e não um eventual processo de descarnamento.

Em relação à decapitação, as únicas possíveis marcas de corte identificadas foram duas pequenas incisões paralelas entre si e localizadas lado a lado na porção superior do processo transverso direito da sexta vértebra cervical e no ramo da mandíbula. Ambas apresentam oito milímetros de comprimento, sendo uma ligeiramente mais profunda que a outra. Considerando-se o contexto de 
amputação, parece razoável assumir que essas incisões sejam de fato marcas de corte.

Ainda assim, caso a amputação tivesse sido feita exclusivamente por meio de instrumentos cortantes, esperaríamos uma profusão de marcas de corte bem definidas e profundas nas vértebras cervicais, particularmente naquelas próximas ao ponto de seccionamento. Entretanto, isso não foi observado. Alternativamente, sugere-se que instrumentos de corte agudo tenham sido utilizados majoritariamente para a remoção dos músculos e tendões do pescoço com o objetivo de expor a parte esqueletal deste último. Uma vez que a coluna cervical foi exposta, a separação da cabeça propriamente dita não teria sido feita com o uso de instrumentos cortantes, mas sim por torção (rotação) em torno do eixo do pescoço. Esse processo de rotação é perfeitamente capaz de romper a medula e os tecidos moles, levando à separação da cabeça.

\section{Discussão e conclusões}

De acordo com a revisão apresentada aqui, fica claro que a maioria dos casos de crânios individualizados está localizada numa área geográfica consideravelmente restrita (noroeste dos Andes). Esse quadro levou a uma visão segundo a qual a prática de individualização de crânios, em geral, e a da decapitação, em particular, teriam uma origem andina e estariam restritas a essa região em tempos pré-coloniais. Segundo Cordy-Collins (1992: 208) "decapitation is a concept that is essentially pan-Andean". No mesmo sentido, Ferguson (1990: 247) afirma que "[t]he taking and shrinking of enemies' heads is an ancient practice among Jivaroan peoples, apparently a survival of what was once a widespread pre-Columbian practice among peoples of and around the northern Andes”, e Jandial et al. (2004: 1215) alegam que "[t]he evidence suggests that the Jivaro-Shuar, far from developing the technique on their own in isolation, are merely the last group to retain a custom widespread in northwestern South America". Conlee (2007: 438) afirma que:

\begin{abstract}
Decapitation was a common type of ritual sacrifice in the ancient Andes. Images of disembodied heads and decapitation were ubiquitous in the art of the Nasca culture, and the large numbers of physical remains of trophy heads found in the archaeological record of the area are unprecedented.
\end{abstract}

Ou seja, parece haver uma tendência na literatura em apontar a região andina não só como o local de origem, mas também como o lugar no qual essas práticas se expressaram de maneira mais clara.

Nesse cenário, a Lapa do Santo assume um importante papel cautelar ao mostrar que essa visão é fruto de um viés arqueológico e não reflete, de forma plena, a natureza subjacente ao fenômeno. Notadamente, os casos da Lapa do Santo deixam claro que tanto o uso de crânios individualizados em cerimônias ou rituais como a própria prática de decapitação não estavam restritos à região andina. Mais do que isso, enquanto as práticas de manipulação do corpo de forma geral são observadas desde o início do Holoceno nos Andes (Llagostera 2003; Santoro et al. 2005), o caso mais antigo de decapitação em toda a América estava datado em cerca de 4000 AP (Engel 1963). O sítio Ásia 1 está localizado na costa central do Peru, região em que, posteriormente, a prática da decapitação atingiria sua expressão mais intensa no subcontinente, ${ }^{5}$ oferecendo suporte a uma suposta origem andina dessa prática.

Entretanto, os casos dos crânios individualizados na Lapa do Santo estão diretamente datados em cerca de 9500 AP e são, portanto, 5000 anos mais antigos do que os esqueletos encontrados em Ásia 1 ou Aguazuque (que, inclusive, não foram datados diretamente). Além dos quatro casos nos quais os crânios foram individualizados e encontrados em "contexto secundário", é importante ressaltar que foi encontrado um crânio plenamente articulado, caracterizando de forma indubitável um caso de decapitação. Ou seja, a

5 De acordo com Carmichel (1994: 84), citado por Verano (1999), entre 5\% e 10\% da população era decapitada durante o período nazca. 
A prática de individualização de crânios e de decapitação na região de Lagoa Santa durante o Holoceno Inicial (Brasil) R. Museu Arq. Etn., 28: 86-108, 2017.

Lapa do Santo não apenas expande em milhares de quilômetros a área de ocorrência dessa prática na América do Sul pré-colonial, como dobra sua profundidade temporal.

Outro aspecto importante é o significado desses crânios individualizados e dessas cabeças decapitadas. Pretender conhecer o que pensavam os indivíduos que levavam a cabo a remoção e a cura dos elementos ósseos é uma tarefa que não pode gerar nada além de frustração, especialmente quando não existem evidências disponiveis de outra natureza, como grafismos. Ainda assim, num nível mais abrangente, algumas interpretações são comumente oferecidas. De forma geral, a discussão gira em torno da identidade da pessoa decapitada, que poderia ser tanto um ancestral venerado quanto um inimigo derrotado, um criminoso executado ou uma vítima de sacrifício. Conforme colocado por Tung e Knudson (2008: 915),

an isolated human head on display is a potentially powerful symbol, yet the meanings associated with it may vary greatly between groups and individuals, depending not only on culturally constructed notions of what dismembered bodies represent but also on how and from whom heads were taken. A head could be obtained by decapitating an enemy, by carefully removing it from an ancestor's corpse, or by collecting it after a criminal has been beheaded. The significance of this particular body part-as an icon of victory over an enemy, a loving memento of one's kin, or an emblem of judicial authority-invites inquiry into how the body and body parts are used to achieve particular ends.

Na maioria dos casos arqueológicos citados anteriormente, não existe consenso sobre qual é a explicação mais cabível. Entre os moche, por exemplo, a rica iconografia deixa pouca dúvida de que as cabeças-troféu eram obtidas nos campos de batalha. Ainda assim, há divergência se essas eram batalhas rituais entre os próprios moche ou batalhas "verdadeiras" entre os moche e outros povos (Sutter \& Cortez 2005). Entre os nazca, existem autores que defendem que as cabeças pertenciam a inimigos derrotados e outros que sugerem que eram ancestrais venerados, não havendo consenso entre eles (Browne, Silverman \& Garcia 1993; Verano et al. 1999, 2008; DeLeonardis 2000; Conlee 2007; Knudson et al. 2009). Não existe nenhuma maneira direta e imediata para decidir qual é a explicação mais cabível, sendo necessário que cada caso seja analisado contextualmente, levando-se em consideração o maior número possível de fontes de informação.

Nesse sentido, estudos biométricos, demográficos e de estilo e qualidade de vida podem ser de grande valia. Sutter e Cortez (2005), por exemplo, advogaram que no caso moche as cabeças rituais eram obtidas em batalhas com inimigos externos, já que as análises de biodistâncias mostravam considerável diferenciação das cabeças-troféu. No caso huari, Tung (2008) defendeu que as cabeças pertenciam aos inimigos derrotados, baseando-se na presença de sinais indicativos de violência interpessoal e na quase total ausência de crânios de indivíduos do sexo feminino.

Utilizando uma lógica análoga, uma vez que na Lapa do Santo todos os três crânios individualizados para os quais foi possível estimar o sexo eram masculinos (14, 17 e 26), seus crânios deveriam ter sido obtidos de inimigos derrotados. Entretanto, além de crânios adultos, esses grupos também individualizavam crânios de indivíduos subadultos (vide sepultamentos 9 e 23). Além disso, as cabeças-troféu descritas na literatura apresentam modificações no sentido de permitirem que algum tipo de "alça" fosse instalado nelas para que pudessem ser carregadas. Daí a presença de orifícios nas cabeças-troféu descritas na seção anterior entre os nazca e os huari. Já na Lapa do Santo, não foi observado nenhum tipo de orifício nos crânios individualizados. $\mathrm{O}$ único caso em que tais orifícios foram observados foi na mandíbula de um subadulto do Sepultamento 18, que dificilmente desempenhava um papel de guerreiro.

Além disso, e esse é um ponto nevrálgico, na Lapa do Santo os crânios individualizados faziam parte de um conjunto mais amplo de elementos ósseos que eram removidos e realocados (Strauss 2010, 2011, 2012, 2014, 2017; Strauss et al. 2011, 2015, 2016, 2018a, 2018b). Ou seja, ao contrário do caso das 
cabeças-troféu stricto sensu, no qual estas eram o ator central e o próprio fim da remoção do crânio, na Lapa do Santo esse era apenas um elemento que, junto com outros, compunha o mise-en-scène mortuário. Assumindo-se que os "fins" dos rituais da Lapa do Santo eram justamente reificar pares de oposição através dos ossos humanos (Strauss 2016a, 2016b), ele só poderia ser realizado pela conjunção de todos esses ossos. É importante ressaltar que, em todos os casos, os crânios individualizados estavam acompanhados de outros ossos. Mesmo no caso do Sepultamento 26, no qual o crânio estava plenamente articulado com a mandíbula e as vértebras cervicais, ele estava acompanhado das duas mãos amputadas, que engendravam a dicotomia expressa pelos pares de oposição que caracterizam esses enterros da Lapa do Santo. As duas mãos foram colocadas em dupla oposição em relação ao crânio, já que uma estava com os dedos voltados para baixo e a palma voltada para o crânio, e a outra, com os dedos voltados para cima e a palma voltada para o lado oposto. Ou seja, mesmo no caso mais "prístino" de decapitação, fica claro que a reificação dos pares de oposição era um elemento importante.

Mais do que isso, ao reificar esses pares de oposição, a própria cosmovisão desses povos estava sendo expressa, somatizada, comunicada e (re)produzida. De acordo com Brown (2010: 32):

When we reflect on the deep and myriad cultural connections that bones have as an essence of human life, we can readily recognize the extent to which hard organic residues of life constitute a potent cultural resource in ancient societies... Human bones are used in ways that conform to the ideological conventions that dominated each society ... Conceptions about the cosmos commonly influence the burial display of human bones. By that I mean that the deployment of secondary human interments into conceptual designs replays key features of how the universe is organized, how it originated, and the plotline contained in myths that charter access to spiritual power.

Um aspecto importante dessa interpretação é que, para a disposição dos ossos ser capaz de funcionar como uma referência gráfica e lógica que possa orientar a narrativa cuja pretensão é ordenar o cosmos e garantir sua perpetuação, ela precisa ser vista e, portanto, a exibição pública desses arranjos de ossos devia ser uma parte central das cerimônias. Colocado de outra forma, existe um caráter estético subjacente à organização desses ossos, que só faz sentido caso fosse parte da encenação funerária a sua exposição ou exibição. Uma lógica similar a essa, mas aplicada de forma inversa, foi defendida por Maschner e Reedy-Maschner (2007: 32), para quem os troféus são "symbols of successes in interpersonal violence and warfare. Their visibility is critical to their power to give the holder greater access to the rewards of increased status".

De qualquer maneira, independentemente das interpretações possíveis, não resta dúvidas de que essa prática devia ter grande importância entre as populações que ocuparam a região de Lagoa Santa há mais de 9000 anos. Conforme colocado por DeLeonardis (2000: 363): "While interpretation may differ as to the nature of removal (victim or willing participant), or the agent of decapitation (ritual specialist or enemy warrior), the preponderance of heads clearly suggests a cultural emphasis on their importance".

As práticas observadas na Lapa do Santo durante o Holoceno Inicial mostram que, na ausência de uma arquitetura sofisticada ou de ricos acompanhamentos funerários, a elaboração dos rituais mortuários passava pelo uso do próprio corpo do falecido como um símbolo. No que se refere ao registro arqueológico, isso é expresso não apenas na ocorrência de crânios individualizados, mas também de sepultamentos desarticulados, fardos de ossos (compostos por até dois indivíduos), marcas de corte, chanfros, extração de dentes, seleção de partes anatômicas, exposição ao fogo e aplicação de ocre. Ao mesmo tempo, a presença de esqueletos articulados, entre os quais está o caso mais antigo de decapitação em todo o continente americano, atesta que a seleção de partes anatômicas e sua consequente remoção eram praticadas logo após a morte, enquanto os tecidos moles ainda estavam presentes. Posteriormente, os ossos eram realocados 
A prática de individualização de crânios e de decapitação na região de Lagoa Santa durante o Holoceno Inicial (Brasil) R. Museu Arq. Etn., 28: 86-108, 2017.

e dispostos de acordo com uma série de princípios muito bem definidos.

Em muitas sociedades humanas, resíduos orgânicos constituíam um poderoso recurso cultural. A manipulação e a organização de ossos humanos e partes do corpo foi comumente utilizada para reificar princípios cosmológicos (Brown 2010). Notadamente, por meio desses procedimentos e arranjos procedia-se à reificação de diretrizes lógicas que, possivelmente, refletiam aspectos da própria cosmovisão daqueles grupos. Os sepultamentos desarticulados do chamado Padrão Funerário da Lapa do Santo 2 (PFLS-2), ao qual pertencem os crânios individualizados que são o foco desta contribuição, apresentam uma lógica dicotômica que orienta (prescreve) a forma como os ossos são organizados (Strauss 2010). Essa lógica é inferida pela presença da dupla dicotomia entre "adulto" e "subadulto" e entre "crânio" e "pós-crânio", a dicotomia entre "diáfise" e "epífise" e a dicotomia entre "dente" e "alvéolo vazio".

Esse sistema, no qual se enfatizam pares de oposições, atribui, inevitavelmente, um tom levi-straussiano (isto é, estruturalista) à lógica adotada (Levi-Strauss 1966, 1969). Conforme colocado por Héretier (1982: 158-159), parte-se do pressuposto de que a "simbologia elementar do idêntico e do diferente" é ferramenta básica na fundamental tarefa com que se depara cada sociedade de gerar sua autorrepresentação. Mais especificamente, é fortuito notar que entre dois dos principais grupos macrolinguísticos do Brasil, notadamente os jê e os tupis, ainda que essa simbologia elementar esteja presente em ambos, existe um contraste profundo na forma pela qual essa lógica do digital impacta a morfologia social.
Entre os tupis, ainda que essa dialética se expresse de forma magistral no plano estritamente cosmológico (Castro 1992), ela tem pouca impressão na organização social propriamente dita. Por outro lado, os grupos jê constituem sociedades nas quais essa lógica se reifica da maneira mais intensa e explícita. Nas palavras de Viveiro de Castro (1992: 5), entre os grupos jê "encontramos o máximo desenvolvimento de oposições complementares nas categorias sociais e valores cosmológicos, oposições que se dobram, desdobram, interceptam, e ecoam umas às outras numa vertiginosa progressão barroca". Trata-se, portanto, do clássico contraste entre sociedades "metafóricas" e sociedades "metonímicas", entre sociedades "totêmicas" e sociedades "sacrificais", e, finalmente, entre sociedades "legiveis" e sociedades "imperceptíveis” (Castro 1992: 11).

Partindo do necessário reconhecimento dos limites aos quais estão submetidas as interpretações de teor mais subjetivo quando se está próximo da fronteira do Pleistoceno com o Holoceno, proponho que o que vislumbramos nos sepultamentos do PFLS-2 são justamente elementos que faziam parte dessa "vertiginosa progressão barroca" a que se refere Viveiro de Castro. Sem nunca esquecer que estamos no plano das mais puras conjecturas e que possivelmente jamais seremos capazes de testar a validade de tais hipóteses, proponho que, assim como os grupos jê atuais, os grupos responsáveis pelo PFLS-2 também tinham uma organização social de morfologia bem cristalizada e legivel, que se fundamentava numa dialética estruturalista explícita (Maybury-Lewis 1979). Tal situação contrasta com a possibilidade mais amorfa, tão bem representada por muitos dos grupos tupis (Castro 1992).

STRAUSS, A; OLIVEIRA, R. E. The practice of skull individualization and decapitation in Lagoa Santa region during early Holocene (east-central Brazil). R. Museu Arq. Etn., 28: 86-108, 2017.

Abstract: Few Amerindian habits impressed the European colonizers more than the taking and displaying of human body parts, especially when decapitation was involved. In South America, the oldest decapitation is reported in the Andean region and dates to ca. 3000 BP at the site Asia 1, Peru. Since all other South American archaeological cases occur in the Andes (e.g., Nazca, 
Moche, Wari, Tiwanaku) it was assumed that decapitation was an Andean phenomenon, in both its origins and in its most unambiguous expression. In the present contribution we provide a literature review of the available evidence on the pre-historic practice of decapitation and skull individualization in South America. Here we report cases of individualized skulls found in Lapa do Santo and dated to 9000-9500 cal BP (95.4\% interval). These cases, including the oldest case of decapitation in the New World, result in a re-evaluation of previous interpretations of these practices in South America on what concerns its origins and geographical distribution in the continent.

Keywords: Archaeology; Anthropology; History; Lapa do Santo; Ritual.

\section{Referências bibliográficas}

Alva, W. 1994. Sipan. Cerveceria Backus \& Johnston, Lima.

Arnold, D.Y.; Hastorf, C. 2008. Heads of state: icons, power and politics in the ancient and modern Andes. Left Coast Press, Walnut Creek.

Baraybar, J. 1987. Cabezas trofeo Nasca: nuevas evidencias. Gaceta Arqueologica Andina, 15: 6-10.

Becker, S.K.; Alconini, S. 2015. Head extraction, interregional exchange, and political strategies of control at the Site of Wata, Kallawaya Territory, Bolivia, during the transition between the Late Formative and Tiwanaku periods (A.D. 200-800). Latin American Antiquity, 26 (1): 30-48.

Blom, D.; Janusek, J. W. 2004. Making place: humans as dedications in Tiwanaku. World Archaeology, 36 (1): 123-41.

Bourget, S. 1998. Pratiques sacrificielles et funéraires au site moche de la Huaca de la Luna, Cote Nord du Pérou. Bulletin de l'Institut Français d'Études Andines, 27 (1): 41-74.

Bourget, S. 2001. Children and ancestors: ritual practices at the Moche site of Huaca de la Luna, North coast of Peru. In: Benson, E.; Cook, A. (Eds.). Ritual sacrifice in ancient Peru. University of Texas Press, Austin, 93-118.
Browne, D.M.; Silverman, H.; Garcia, R. 1993. A cache of 48 nasca trophy heads from Cerro Carrapo, Peru. Latin American Antiquity, 4 (3): 274-294.

Brown, J.A. 2010. Cosmological layouts of secondary burials as political instrument. In: Sullivan L.P.; Mainfort R.C. (Eds.). Mississippian Mortuary Practices - beyond hierarchy and the representationist perspective. The University Press of Florida, Florida.

Bryan, A. 1993. The sambaqui at Forte Marechal Luz, state of Santa Catarina, Brazil. In: Bryan, A. (Ed.). Brazilian Studies. Oregon: Center for Study of the First Americans, 1-114.

Burger, R. 1984. The prehistoric occupation of Chavion de Huantar, Peru. University of California Press, Berkeley.

Butters, L.J.C. 2005. Las señoras de San José de Moro: rituales funerarios de mujeres de élite en la costa norte del Perú. In: Landazuri, M.C; Astete, G. (Eds.). Divina y humana, la mujer en los antiguos Perú y México. Ministerio de Educación, Lima, 18-29.

Carlos, R. 2004. El área 33 y la Tumba de los Chamanes de San José de Moro. In: Castillo, L.J. (Ed.). Programa arqueológico San José de Moro, temporada 2004. Pontificia Universidade Católica del Perú, Lima, 110-125. 
A prática de individualização de crânios e de decapitação na região de Lagoa Santa durante o Holoceno Inicial (Brasil) R. Museu Arq. Etn., 28: 86-108, 2017.

Carmichael, P. 1995. Nasca burial patterns: social structure and mortuary ideology. In: Dill, T. (Ed.). Tombs for the living: andean mortuary practices. Dumbarton Oaks, Washington, 161-187.

Castro, E.V. 1992. From the enemy's point of view: humanity and divinity in an Amazonian Society. University of Chicago Press, Austin.

Chacon, R.; Dye, D. 2007. The taking and displaying of human body parts as trophies by Amerindians. Springer, New York.

Coelho, V.P. 1972. Enterramento de cabeças da cultura Nasca. Tese de Doutorado. Escola de Comunicação e Artes, Universidade de São Paulo, São Paulo.

Conlee, C. A. 2007. Decapitation and rebirth: A headless burial from Nasca, Peru. Current Anthropology, 48 (3): 438-445.

Conlee, C. A. et al. 2009. Identifying foreigners versus locals in a burial population from Nasca, Peru: an investigation using strontium isotope analysis. Journal of Archaeological Science, 36: 2755-2764.

Cordy-Collins, A. 1992. Archaism or tradition? The decapitation theme in Cupisnique and Moche iconography. Latin American Antiquity, 3: 206-20.

Cordy-Collins, A. 2001. Decapitation in Cupisnique and early Moche societies. In: Benson, E.; Cook, A. (Eds.). Ritual sacrifice in ancient Peru: new discoveries and interpretation. University of Texas Press, Austin, 21-33.

Correal, G. 1990. Aguazuque evidencias de cazadores, recolectores y plantadores en la altiplanice de la cordillera oriental. Fundación de Investigaciones Arqueológicas Nacionales, Bogotá.

Couture, N.; Sampeck, K. 2003. Putuni: history of palace architecture at Tiwanaku. In: Kolata, A. (Ed.). Tiwanaku and its hinterland: archaeology and paleoecology of an Andean civilization. Smithsonian Institution Press, Washington, 226-263.
DeLeonardis, L. 2000. The body context: interpreting early Nasca decapitated burials. Latin American Antiquity, 11 (4): 363-386.

DeNiro, M.J.; Epstein, S. 1978. Influence of diet on the distribution of carbon isotopes in animals. Geochimica et Cosmochimica Acta, 42 (5): 495-506.

Donnan, C. 1995. Moche funerary practices. In: Dillehay, T.D. (Ed.). Tombs for the living: andean mortuary practices. Dumbarton Oaks, Washington, 111-158.

Donnan, C. 2001. Moche Burials uncovered. National Geographic, 199 (3): 58-73.

Donnan, C. 2007. Moche tombs at Dos Cabezas. Monograph 59. Cotsen Institute of Archaeology; University of California, Los Angeles.

Donnan, C.; Mackey, C.J. 1978. Ancient burial patterns of the Moche Valley, Peru. University of Texas Press, Austin.

Donnan, C.; McClelland, D. 1979. The burial theme in Moche iconography. Studies in pre-Columbian art and archaeology, 21: 5-46.

Drusini, A.; Baraybar, J. 1991. Anthropological study of Nasca trophy heads. Homo, 41 (3): 251-265.

Engel, F. 1963. A preceramic settlement on the central coast of Peru: Asia. Transactions of the American Philosophical Society, 53 (3): 3-139.

Fausto, C.; Rodgers, D. 1999. Of enemies and pets: warfare and shamanism in Amazonia. American Ethnologist, 26 (4): 933-956.

Ferguson, R.B. 1990. Blood of the Leviathan: western contact and warfare in Amazonia. American Ethnologist, 17 (2): 237-257.

Gabarain, M.T. 1962. Los Mundurucu. Revista de Indias, 89-90: 321-40.

Giesela, H.; Hecker, W. 1992. Huesos humanos como ofrendas mortuaorias y uso repetido de vasijas. Baessler-Archiv Neue Folge, 40: 171-195. 
Harner, M.J. 1962. Jívaro Sould. American Anthropologist, 64: 258-72.

Hartt, C.F. 1881. Contribuições para a etnologia do Vale do Amazonas. Arquivos do Museu Nacional, 6: 1-174.

Héretier, F. 1982. The symbolics of incest and its prohibition. In: Izard, M.; Smith, P. (Eds.). Between belief and transgression: structuralist essays in religion, history and myth. The University of Chicago Press, Chicago.

Jandial, R. et al. 2004. The science of shrinking human heads: tribal warfare and revenge among the South American Jivaro-Shuar. Neurosurgery, 55 (5): 1215-1220.

Kauffman, D. et al. 1989. Andes amazónicos: sitios intervenidos por la Expedición Antisuyo/86. Museo Nacional de Antropología y Arqueología; Instituto de Investigaciones Antropológicas, Lima.

Knudson, K.J. et al. 2009. The geographic origins of Nasca trophy heads using strontium, oxygen, and carbon isotope data. Journal of Anthropological Archaeology, 28: 244-257.

Kruse, A. 1934. Mundurucu moieties. Primitive Man, 7: 51-57.

Leopoldi, J.S. 2007. A guerra implacável dos Munduruku: elementos culturais e genéticos na caça aos inimigos. Avá, 11: 169-189.

Lessa, A. 2007. Rituais de sacrifício: a sobrevivência de uma antiga dimensão do corpo humano. História, Ciências, Saúde-Manguinhos, 14 (3): 907-919.

Levi-Strauss, C. 1966. The savage mind. The University of Chicago Press, Chicago.

Levi-Strauss, C. 1969. The raw and the cooked: introduction to the science of mythology. The University of Chicago Press, Chicago.

Llagostera, A. 2003. Patrones de momificación Chinchorro en las colecciones Uhle y Nielsen. Chungara, 35 (1): 5-22.
Lumbreras, L. 1981. The stratigraphy of the open sites. In: MacNeish, R. (Ed.). Prehistory of Ayacucho Basin, Peru, Volume II: excavations and chronology. Ann University of Michigan Press, Arbor, 167-198.

Manzanilla, L.; Woodard, E. 1990. Restos humanos asociados a la Pirámide Akapana (Tiwanaku, Bolivia). Latin American Antiquity, 1: 133-149.

Maschner, H.D.G.; Reedy-Maschner, K.L. 2007. Heads, women, and the baubles of prestige: trophies of war in the arctic and subarctic. In: Chacon, R.; Dye D. (Eds.). The taking and displaying of human body parts as trophies by amerindians. Springer Press, New York.

Maybury-Lewis, D. 1979. Dialectical societies: the Gê and Bororo of central Brazil. Harvard University Press, Harvard.

Menget, P. 1993. Notas sobre as cabeças Munduruku. In: Castro, E.V.; Cunha, M.C. (Eds.). Amazônia: etnologia e história indígena, 311-321.

Millaire, J.-F. 2004. The manipulation of human remains in Moche society: delayed burials, grave reopening, and secondary offerings of human bones on the Peruvian North coast. Latin American Antiquity, 15: 371-388.

Murphy, R.F. 1957. Intergroup hostility and social cohesion. American Anthropologist, 59: 1018-1035.

Nelson, A.J. 1998. Wandering Bones: archaeology, forensic science and Moche burial practices. International Journal of Osteoarchaeology, 8 (3): 192-212.

Neves, W.A.; Hubbe, M.; Correal, G. 2007. Human skeletal remains from Sabana de Bogota, Colombia: a case of paleoamerican morphology late survival in south america? American Journal of Physical Anthropology, 133 (4): 1080-1098.

Nystrom, K.C.; Buikstra, J. E.; Muscutt, K. 2010. Chachapoya mortuary behavior: a consideration of method and meaning. Chungara (Arica), 42: 477-95. 
A prática de individualização de crânios e de decapitação na região de Lagoa Santa durante o Holoceno Inicial (Brasil)

R. Museu Arq. Etn., 28: 86-108, 2017.

Ogburn, D. 2007. Human trophies in the late pre-Hispanic Andes: striving for status and maintaning power among the Incas and other societies. In: Chacon, R.; Dye, D. (Eds.). The taking and displaying of human body parts as trophies by Amerindians. Dumbarton Oaks, Washington, 505-522.

Petersen, J.B.; Crock, J.G. 2007. "Handsome death": the taking, veneration and consumption of human remains in the insular Caribbean and greater Amazonia. In: Chacon, R.; Dye, D. (Eds.). The taking and displaying of human body parts as trophies by Amerindians. Springer, New York, 547-574.

Proulx, D. 1971. Headhunting in ancient Peru. Archaeology, 24 (1): 16-21

Proulx, D.A. 1999. Nasca headhunting and the ritual use of trophy heads. In: Rickenbach, J. (Ed.). Nasca: Geheimnisvolle Zeichen im Alten Peru. Museum Rietberg Zürich, Zürich, 79-87.

Proulx, D.A. 1989. Nasca trophy heads: victims of warfare or ritual sacrifice. In: Diana Tkaczuk, C.; Vivian, B.C. (Eds.). Cultures in conflict: current archaeological perspectives. The Archaeological Association of the University of Calgary, Calgary, 73-85.

Proulx, D.A. 2001. Ritual uses of trophy heads in ancient Nasca society. In: Benson, E.; Cook, A. (Eds.). Ritual sacrifice in ancient Peru. University of Texas Press, Austin, 119-136.

Pugliese, F.; Valle, R. 2015. A gestão do patrimônio arqueológico em territórios indígenas: a resistência munduruku e a preservação do patrimônio cultural frente a territórios tradicionalmente ocupados. Revista de Arqueologia, 28 (1): 30-51.

Reichlen, B. 1973. Un cráneo de Chavín de Huántar, Perú. Revista del Museo Nacional de Lima, 39: 143-151.

Rosaldo, M.Z. 1983. The shame the of headhunters and the autonomy of self. Ethos, 11 (3): 135-151.
Rubenstein, S. L. 2007. Circulation, accumulation and the power of the Shuar shrunken heads. Cultural Anthropology, 22 (3): 357-399.

Santoro, C.M. et al. 2005. Archaic funerary pattern or postdepositional alteration? The Patapatane burial in the highlands of South Central Andes. Latin American Antiquity, 16 (3): 329-346.

Santos, S.F. et al. 2007. Os munduruku e as cabeçastroféu. Revista do Museu de Arqueologia e Etnologia, 17: 365-380.

Sauvageau, A. et al. 2009. Jivaro tsantsas or shrunken head: an expertise of authenticity evaluation. The American Journal of Forensic Medicine and Pathology, 30 (1): 72-74.

Steel, D. 1999. Trade goods and Jivaro warfare: the Shuar 1850-1957, and the Achuar, 1940-1978. Ethnohistory, 46(4): 745-776.

Strauss A. 2010. As práticas mortuárias dos caçadorescoletores pré-históricos da região de Lagoa Santa (MG): um estudo de caso do sítio arqueológico "Lapa do Santo". Dissertação de Mestrado. Instituto de Biociências, Universidade de São Paulo, São Paulo.

Strauss A. 2011. As práticas mortuárias dos caçadores coletores pré-históricos da região de Lagoa Santa (MG): um estudo de caso do sítio arqueológico Lapa do Santo. Revista Brasileira de Arqueologia da $S A B, 24$ (1): 136-139.

Strauss A. 2012. Interpretative possibilities and limitations of the Saxe/Goldstein hypothesis. Boletim do Museu Paraense Emilio Goeldi Ciências Humanas, 7 (2): 525-546.

Strauss A. 2014. As práticas mortuárias dos primeiros sul-americanos. Arquivos do Museu de História Natural e Jardim Botânico da UFMG, 23 (1): 89-134

Strauss, A. 2016a. Os padrões de sepultamento do sítio arqueológico Lapa do Santo (Holoceno Inicial, Brasil). Boletim do Museu Paraense Emilio Goeldi Ciências Humanas, 11 (1): 243-276. 
Strauss, A. 2016b. As práticas mortuárias da região de Lagoa Santa: história das pesquisas. In: Da-Gloria, P.; Hubbe, M.; Neves, W.A. (Orgs.). Lagoa Santa: a história das pesquisas na região de Lagoa Santa. Annablume, São Paulo.

Strauss, A. 2017. Burial practices in the Lagoa Santa region: history of research. In: Da-Gloria, P.; Hubbe, M.; Neves W.A. (Eds.). Archaeological and paleontological research in Lagoa Santa. Springer, New York.

Strauss, A. et al. 2011. Two directly dated Early Archaic burials from Pains, State of Minas Gerais, Brazil. Current Research on the Pleistocene, 28: 123-125.

Strauss, A. et al. 2015. The oldest case of decapitation in the New World (Lapa do Santo east-central Brazil). Plos One, 10 (9): e0137456.

Strauss, A. et al. 2016. Early Holocene ritual complexity in South America: the archaeological record of Lapa do Santo (east-central Brazil). Antiquity, 90 (354): 1454-1473.

Strauss, A. et al. 2018a. The Lagoa Santa region archaeological record. In: Auler, A.; Pessoa, P. (Eds.). Lagoa Santa Karst. Springer, New York.

Strauss, A. et al. 2018b. Human skeletal remains from Serra da Capivara, Brasil: a reappraisal of the available evidence and new findings. In: Harvati, K.; Jäger, G.; Rezes-Centeno, H. (Eds.). New perspectives on the peopling of the new world. Kerns, Tübingen.

Sutter, R.C.; Cortez, R.J. 2005. The nature of Moche human sacrifice: a bio-archaeological perspective. Current Anthropology, 46 (4): 521-549.

Taylor, A.C. 1993. Remembering to forget: identity, mourning and memory among the Jivaro. Man, 28: 653-678.

Teixeira-Pinto, M. 1997. Ieipari: sacríficio e vida social entre os índios arara (Caribe). Hucitec, São Paulo; Anpocs Editora UFPR, Curitiba.
Toyne, J. 2011. Interpretations of pre-hispanic ritual violence at Tucume, Peru, from cut mark analysis. Latin American Antiquity, 22 (4): 505-523.

Tung, T.A. 2007. From corporeality to sanctity: transforming bodies into trophy heads in the pre-ceramic Andes. In: Chacon, R. J.; Dye, D. H. (Eds.). The taking and displaying of human body parts as trophies by Amerindians. Springer, New York, 481-504.

Tung, T.A. 2008. Dismembering bodies for display: a bioarchaeological study of trophy heads from the Wari site of Conchopata, Peru. American Journal of Physical Anthropology, 136 (3): 294-308.

Tung, T.A.; Knudson, K.J. 2008. Social identities and geographical origins of Wari trophy heads from Conchopata, Peru. Current Anthropology, 49 (5): 915-925.

Tung, T.A.; Knudson, K. J. 2010. Childhood lost abduction sacrifice trophy heads wari empire. Latin American Antiquity, 21 (1): 44-66.

Verano, J.W. 1986. A mass burial of mutilated individuals at Pacatnamu. In: Donnan, C.; Cock, G. (Eds.). The Pacatnamu Papers, 1: 117-138.

Verano, J.W. 1995. Where do they rest? The treatment of human offerings and trophies in ancient Peru. In: Dillehay, T. (Ed.). Tombs for the living: andean mortuary practices. Dumbarton Oaks, Washington, 189-227.

Verano, J.W. 1998. Sacrificios humanos, desmembramientos y modificaciones culturales en restos osteológicos: evidencias de las temporadas de investigación 1995-96 en Huaca de la Luna. In: Uceda, S.; Mujica, E.; Morales, R. (Eds.). Investigaciones en la Huaca de la Luna 1996. Universidad Nacional de La Libertad, Trujillo, p. 159-171.

Verano, J.W. 2000. Paleopathological analysis of sacrificial victims at the Pyramid of the Moon, Moche River Valley, Northern Peru. Chungará (Arica), 32: 61-70. 
A prática de individualização de crânios e de decapitação na região de Lagoa Santa durante o Holoceno Inicial (Brasil) R. Museu Arq. Etn., 28: 86-108, 2017.

Verano, J.W. 2001a. War and death in the Moche world: osteological evidence and visual discourse. In: Pillsbury, J. (Ed.). Moche Art and Archaeology in Ancient Peru. National Gallery of Art; Center for Advanced Study in the Visual Arts, New Haven; London, 111-125.

Verano, J.W. 2001b. The physical evidence of human sacrifice in ancient Peru. In: Benson, E.P.; Cook, A.G. (Eds.). Ritual sacrifice in ancient Peru. University of Texas Press, Austin, 165-184.

Verano, J.W. 2008a. Communality and Diversity in Moche Human Sacrifice. In: Bourget, S.; Jones, K. (Eds.). The art and archaeology of the Moche: an ancient Andean society of the Peruvian North Coast. University of Texas Press, Austin, 195-213.
Verano, J.W. 2008b. Trophy head-taking and human sacrifice in Andean South America. In: Silverman, H.; Isbell, W.H. (Eds.). Handbook of South American archaeology. Springer, New York, 1047-1060.

Verano, J.W. et al. 1999. Modified human skulls from the urban sector of the pyramids of Moche, northern Peru. Latin American Antiquity, 10 (1): 59-70.

Villagran, X. et al. 2017. Buried in ashes: site formation processes at Lapa do Santo rockshelter, east-central Brasil. Journal of Archaeological Science, 77: 10-34.

Von Ihering, H. 1907. As cabeças mumificadas pelos Mundurukus. Revista do Museu Paulista, 7: 179-201. 